displayed alerting patients and families. Patients were invited to participate by their key worker. Full explanation was given to participants, with consent obtained prior to filming. Patients without capacity were excluded but their relatives included. The Clinical Lead had increased visible presence during the 13 weeks filming across clinical areas ensuring equal access to patient stories.

Results Some clinical staff were reticent, acting as gatekeepers, impacting on opportunities for patients and families, addressed by Clinical Lead's presence. A surprising number of families showed a willingness to talk at intense critical moments in their journey.

Families have valued the lasting legacy this has provided.

'If filming highlighted to others what services are provided I feel it has been of benefit' (Patient)

Conclusions Patients and families value telling their stories and feeling heard. Barriers to participation of patient involvement have reduced as clinical awareness of therapeutic benefits has grown.

\section{P-25 FIVE MINUTES OF FAME: THE PSYCHOSOCIAL IMPACT OF MAKING A TELEVISION DOCUMENTARY}

Russ Hargreaves. ellenor, Gravesend, UK

\subsection{6/bmjspcare-2018-hospiceabs.50}

Background Between January and April 2018, a television production company began filming a 13-week documentary exploring hospice care which aired from May 2018.

Aims During filming - explore the impact of film crew on patient/family experiences. During broadcast - support participants featured in the documentary, ensuring the safety and follow-up of patients and bereaved families.

Methods Patients, carers, staff and volunteers from a selected hospice were approached about filming and offered an opportunity to tell their story. In addition, disclaimers were placed around the hospice with full explanation of the process. Contact details of all featured in the documentary were collected throughout the filming process. Our Communications Team had some editorial control reviewing each draft episode, creating a working plan of patients and families featured, enabling individuals to be contacted prior to broadcast of their particular episode. Bereaved families were invited in for a private screening of their episode five days prior to broadcast.

Results Film crews were sensitive when approaching patients and did so with full consent. All patients and families who consented were keen to tell their story and play a part in the documentary. However, occasionally there was a sense that the presence of cameras changed the nature of the interaction with patients and their relatives. Occasionally, this meant scenarios were 'staged' with some conversations needing to be repeated. For patients filmed during the documentary who subsequently died, families were grateful for forewarning of the broadcast. Most families declined the offer of private screening, although many stated they would record the episode to watch later. Private screenings enabled staff to pick up bereavement risks resulting in onward referral to counselling services.

Conclusion Filming in the hospice environment needs to be handled extremely carefully and sensitively with great consideration and support given to families whose loved ones subsequently die.

\section{P-26 THE SWAN SONG PROJECT}

${ }^{1}$ Nicola Denbow, ${ }^{2}$ Ben Slack. ${ }^{1}$ Marie Curie Hospice, Bradford, UK; ${ }^{2}$ The Swan Song Project, Bradford, UK

10.1136/bmjspcare-2018-hospiceabs.51

The Swan Song Project gives people dealing with end of life and bereavement the opportunity to write and record an original song. A professional songwriter helps every step of the way, the songs are then recorded and participants have the option of keeping them private or sharing them on the project website. Beginning at Marie Curie Hospice Bradford in May 2017 the project has been incredibly powerful in many ways. This presentation will detail the different ways people have engaged with the project and the impact it has made. The song-writing process can be greatly therapeutic as many participants have reported. Some have used the opportunity to communicate beautiful messages to their loved ones which may have been difficult to do face-to-face, some have reflected on their lives and found new perspectives on their value and identity and some have left messages for their children or grandchildren to grow up with. These songs are in the control of the participants and focus on who they are and what they want to say in a time when a lot may be out of their control and focusing on their conditions. The project also works with friends and family dealing with bereavement. The songs can then live on with them for many years to come as a part of their loved ones' legacy.

In this presentation, Project Facilitator Ben Buddy Slack and Lead Nurse at Marie Curie Bradford, Nicky Denbow, will share stories and feedback on the project so far and the impact it has made on participants, their loved ones, the hospice and the wider public. We all lose people and we all connect with music in some way and this project has moved the hearts of many and it is continuing to develop and expand.

\section{P-27 WHAT MATTERS AT THE END OF LIFE? RESULTS FROM COMMUNITY LISTENING EVENTS ON THE ISLE OF MAN}

Giovanna Cruz, Anne Mills, Lottie Morris, Hollie Quaye, Brenda Dougherty, Lonan Oldam, Sarah McGhee. Hospice Isle of Man, Strang, Isle of Man

\subsection{6/bmjspcare-2018-hospiceabs.52}

Background Hospice Isle of Man (IoM) is celebrating its 35th anniversary. To thank the community and to inform the next five-year strategy, the hospice conducted a series of community listening events with the theme of 'What matters to you, matters to us'.

Aims To understand what the public knew about Hospice and learn about their experience; to find out what matters most when confronted with end of life; and to ask how the hospice can best serve the IoM.

Methods Hospice staff approached members of the public at supermarkets and community events at seven locations. Events took place between January and February 2018 during business hours. Demographic data were collected on age and sex. Interviewers recorded responses that were analysed using thematic analysis according to the aims.

Results A total of 278 persons from a population of 83000 provided comments. The majority were female (63\%) and over 55 (68\%), 32\% had used services, and 74\% had general awareness of hospice. Respondents were aware of specialist 
skills and services and/or were supporters. However, only 5\% knew about the range of services and there were misconceptions about who the hospice serves. Others preferred 'not to think about it' or felt there was 'one way out'. Overall, experience with Hospice was positive and many felt it was 'for families'. What mattered to people included: kind, compassionate and effective care, emotional support, person-centred care, equity, the environment, open access, good communication, honesty and helping others talk about death. Hospice can best serve by making services available 'to all who need it', ensure sustainability, by supporting families, friends/ co-workers, schools and by improving transparency of its accounts.

Conclusions Hospice needs to raise awareness of its services. Hospice care is valued and needs to be provided at the right time and place for all who need it.

\section{Communities}

\section{P-28 'YOUTH ENGAGEMENT': IS THERE A PLACE IN PALLIATIVE CARE?}

Abigail Wattam. LOROS, Leicester, UK

\subsection{6/bmjspcare-2018-hospiceabs.53}

Background Youth engagement provides opportunities for young people to make a contribution, raise awareness of services and is a platform for workforce development (HM Government, 2010; Adams, Nursaw \& Smith, 2017). Working with the community raises awareness, supports and 'builds capacity and resilience to care for those at the end of life' (Hospice UK, 2017). Student volunteering is a growing phenomenon, as they seek to enhance their employability skills and contribute to the local community (Williamson, Wildbur, Bell et al., 2017).

Aims To create a programme of activities to support the development of knowledge and skills of young people and to enhance the delivery of different services across the organisation as part of our transforming care agenda.

Methods May 2017 - May 2020: feedback, evaluations, recruitment, engagement figures, fundraising. May 2017 - January 2018: fundraising figures, recruitment, engagement figures. January 2018 - April 2018: recruitment, engagement figures, academic year overview. Progress of youth engagement outlined in the LOROS Community Engagement Strategy/ Action Plan.

Results May 2017 to January 2018 - 49 events $=3575$ engaged, 23 new volunteers, £5096.71 NCS Projects.

Work Experience Student 2017: '...it has taught me so many valuable lessons not just about working in a hospice, but about life and the resilience of the human spirit at the toughest of moments.'

Primary School Project: 'This was one of the most valuable experiences the children have had.'

Hospice School: 'It was an amazing experience and would recommend to anyone thinking of going into health care.'

January 2018 to April 2018 - 28 events=1683 engaged, 131 enterprise volunteers, 18 hospice volunteers.

Next four months - 22 events booked, system input for data of young people, Youth Ambassador Programme.

Conclusion The evaluation and feedback shows a positive change within the hospice environment. We have learnt by developing our safeguarding, work experience and volunteering policies. As a result, further funding is being sought for projects encompassed by this role.

\section{P-29 LIFE MATTERS... SO DOES DEATH. SHOW THE WORLD THAT DYING MATTERS}

${ }^{1}$ Kristy Clayton, ${ }^{2}$ Charlotte Wonders, ${ }^{3}$ Rachael Talbot, ${ }^{4}$ Kay Greene. ${ }^{1}$ George Eliot Hospital NHS Trust, Nuneaton, UK; ${ }^{2}$ NHS Arden and Greater East Midlands CSU, Birmingham, UK; ${ }^{3}$ King Edward VI College, Nuneaton, UK; ${ }^{4}$ Mary Ann Evans Hospice, Nuneaton, UK

\subsection{6/bmjspcare-2018-hospiceabs.54}

An example of true collaboration. Healthcare professionals approached their local college to promote Dying Matters Week 2018. The college and students responded with enthusiasm and excitement. English students produced posters and a press release to start conversations, media students engaged with social media discussions, art students produced an exhibition to give a visual representation of grief by working with patients to create canvas artwork, and the drama students wrote and performed a play. The students stated; 'The project intrigued me. I hadn't heard of Dying Matters before but I know people who have been affected by mental health and grief. I thought it would be a different way to talk about it.' Another student said: 'It made me think a lot more about how we approach death and how it was shown in the play. We really do need to talk about it a lot more. It's kept quiet when someone's passed and I personally find it helpful to talk about it.' The performance and exhibition were attended by professionals, patients and members of the public. One professional stated 'I've worked in palliative care for 25 years and she just got it. When I saw the play, I just cried. It's so genuine.' The patients involved spoke positively about the experience of working with the students and the interaction between the two stages of life. A local MP said 'I'm so impressed at how a group of young people came together to approach a difficult subject. The way that they were able to articulate the way we all feel into such brilliant words, is extraordinary.' The exhibition and play, as well as the whole experience, was unique; to empower young people to think of death as a positive and a part of life, is so important.

\section{P-30 IT'S NOT JUST ABOUT THE DYING: A SCHOOL TWINNING PROJECT HELPING TO DISPEL THE MYTHS OF HOSPICE CARE}

Clare Lawrance, Paula Mitchell. Woking and Sam Beare Hospice, Woking, Surrey, UK

\subsection{6/bmjspcare-2018-hospiceabs.55}

Background As part of on-going service improvement plans, an innovative, collaborative community engagement project was established with school students to showcase the hospice as a positive place where people with life-limiting illnesses can live well, helping dispel myths that hospices are depressing, gloomy places where people only go to die.

Aim (i) Raise students' awareness and support their learning about what hospices do. (ii) Extend community relationships and engagement with Woking Hospice as a charitable organisation. 